\title{
A prospective observational study on cardiovascular risk assessment in type-2 diabetes mellitus patients
}

\author{
Laxmidhar Maharana ${ }^{1}$, Sateesh Kumar Reddy K. ${ }^{2}$, Snigdha Pattnaik ${ }^{1}$, Siraz Ahmed ${ }^{2}$, Divya Teja V., Bhargavi K. ${ }^{2}$, Syed \\ Shabbir Hussain ${ }^{2}$, Manoj Kumar Sethi ${ }^{1 *}$ \\ ${ }^{1}$ School of Pharmaceutical Sciences, Siksha 'O' Anusandhan Deemed To Be University, Bhubaneswar, India. \\ ${ }^{2}$ Smt. Sarojini Ramulamma College of Pharmacy, Mahabubnagar, India.
}

\begin{tabular}{l}
\hline ARTICLE INFO \\
\hline Received on: $11 / 11 / 2018$ \\
Accepted on: $31 / 12 / 2018$ \\
Available online: $18 / 04 / 2019$
\end{tabular}

\section{Key words:}

Cardiovascular disease, type-2 diabetes mellitus, Framingham risk score, ankle braquial index, visceral adiposity index.

\begin{abstract}
Objective: Atherosclerotic cardiovascular diseases were the major culprit in diabetic patients with high mortality rate in non-communicable disease worldwide. Present study was conducted to assess cardiovascular risk among type-2 diabetic patients without the history of cardiovascular disease.

Methods: The present study was conducted on type-2 diabetes patients without history of cardiovascular disease (CVD) and the number of samples was 118 (65 male and 53 female) aged between 36 and 74 years in a teaching hospital of southern part of India. The individual patient risk factors were determined. Framingham cardiovascular risk prediction model was used to calculate the 10 -year risk for CVD. The relationship between Framingham cardiovascular risk score and individual risk factors was determined using chi-square test.

Key findings: Framingham risk score for cardiovascular disease (FRS-CVD) risk assessment model shows $11.01 \%$ were at high risk, $33.05 \%$ were at intermediate risk, and 55.93\% were at low risk for developing CVD in the next 10 years. Visceral adiposity index (VAI), waist circumference, waist height ratio, smoking, systolic blood pressure, diastolic blood pressure contributed significantly to high degree of cardiovascular risk.

Conclusion: The results of our study concluded that, in this population of patient with type- 2 diabetes mellitus, the estimated cardiovascular risk in relationship with the central obesity, but not with glycemic control parameters. The use of CVD assessment tools like Framingham risk score, VAI, and ankle braquial index can prevent the diabetic patient from CVD.
\end{abstract}

\section{INTRODUCTION}

Human environment, behavior, lifestyle, and dietary changes were contributing to accelerate the incidence of diabetes mellitus (Mary Grace et al., 2014). The hazard of cardiovascular mortality increases twofold in the individuals with type II diabetes mellitus as with that of the diabetic free individuals. The type II diabetic individuals possess two to six times increased incidences of CVD than non-diabetic patients (Haffner et al., 1998; Sarwar et al., 2010, Seshasai et al., 2011). While looking into the fact

\section{*Corresponding Author}

Manoj Kumar Sethi, School of Pharmaceutical Sciences, Siksha 'O'

Anusandhan Deemed To Be University, Bhubaneswar, India.

E-mail:manojsethi@soa.ac.in about life expectancy, it is adjudged that there is a decreased life expectancy of nearly 4.8 years in patient group in comparison to normoglycemic individuals ( $\mathrm{Gu}$ et al., 1999). Notwithstanding the fact that the increased survival rate of patients is the resultant of better management, but long term micro-vascular and macrovascular complications which are unavoidable (Gu et al., 1998). It is also estimated that the diabetic individuals associated with cardiac disorder possess worst prognosis for survival and depreciation of quality life of patients than CVD patients without diabetes mellitus. Subsequently hyperglycemic patients were deliberated having equal risk to that of the normoglycemic patients with history of CVD (Grundy et al., 1999).

Grouped classification of patients as per their hazard for cardiovascular illness could congratulate the counteractive action or hindrance of cardiovascular events, and furthermore weakens 
the disease condition. The nearness of various alarming risks in diabetic patients related with cardiovascular ailment weights on the appraisal of individual aggregate burden of risk instead of depending on the level of a specific risk factor (Grundy et al., 1998).

A number of risk prediction algorithms (Conroy et al., 2003; Hippisley-Cox et al., 2008; Ridker et al., 2007) have developed to estimate the forthcoming CVD risk but their implementation in primary care setting remains challenging (NCEP-ATP III, 2002). The gender specific Framingham risk prediction model is one of the most widely used risk assessment tools worldwide. It is based on the evaluation of the findings of Framingham study conducted among the Caucasian population (Bitton and Gaziano, 2010).

The rationale of current research was to analyze the cardiovascular risk which can add value for patient's quality of life and clinician's effective management skill. This can give a platform to opt best therapeutic management strategy for health care providers. The results of this study can motivate patients to maintain a healthy life style which can reduce the complications of above offense. As diabetes mellitus usually associated with several co-morbidities of cardiovascular health, there is a great demand for the development of cardiovascular risk evaluation approaches.

An attempt has been made with the objective of evaluation of the 10 years of risk in type II diabetic related to heart and blood vessel without any history of the same based on Framingham prediction model and to classify the patients risk using various parameters like visceral adiposity index (VAI), ankle brachial index (ABI), waist height ratio (WHtR), and waist hip ratio (WHR). Final aim to evaluate the statistically significant risk factors for CVD.

\section{METHODS}

This is a prospective observational study conducted in both inpatient and outpatient population of Endocrinology Department of SVS Medical College and Hospital, Mahabubnagar, Telangana over a period of 6 months from October 2017 to March 2018. This included 118 diabetic patients (65 males and 53 females) aged between 36 and 74 years. The method of sampling was random cluster sampling. Cochran formula was introduced to estimate the sample size (Cochran, 1977). The data were collected majorly from patient case record forms on the regular basis. Review and follow-up of the same were done after the first consultation. Patients were diagnosed as diabetes only if their fasting blood glucose levels were $\geq 126 \mathrm{mg} / \mathrm{dl}$ (ADA, Diabetes care, 2005). Patients having past history of any cardiovascular events were excluded from the study. The present research was ethically approved by the institutional ethics committee of the hospital (ref. no- SVSMC/IEC/014/2017). Prior to data collection, the purpose of the study was explained to all the subjects and caregiver. Signed informed consent was obtained after assuring the confidentiality form the participating individuals.

Standard techniques of Weiner and Lourie (1981) were used for anthropometric measurements. Height and body weight were measured nearest to $0.1-\mathrm{cm}$ width fixed stadiometer and a weighing scale to the nearest of $0.5 \mathrm{~kg}$, respectively. Body mass index (BMI) was calculated by dividing the bodyweight by the height squared $\left(\mathrm{kg} / \mathrm{m}^{2}\right)$. Waist and hip circumferences were calculated using the flexible steel tape. WHR and WHtR were also calculated (Knowles et al., 2011). Berlin questionnaire was used for the assessment of sleep apnea (Matthew et al., 2011). Central obesity was evaluated by using waist circumference, WHtR and WHR and VAI (Ashwell, 2005; WHO tech. rep. 916, 2003). VAI is the indirect expression of insulin sensitivity and visceral adiposity function. It is calculated on the basis of waist circumference, BMI, triglycerides, and high density lipoprotein (HDL) levels. VAI is an important tool for identification of association between visceral adiposity dysfunction with cardio metabolic risk (Marco et al., 2010). Following formulae were used to identify the VAI in both males and females.

$$
\begin{aligned}
\text { Male }= & \{\mathrm{WC} / 39.68+(1.88 \times \mathrm{BMI})\} \times(\mathrm{TG} / 1.03) \times \\
& (1.31 / \mathrm{HDL}) \\
\text { Female }= & \{\mathrm{WC} / 36.58+(1.89 \times \mathrm{BMI})\} \times(\mathrm{TG} / 0.81) \times \\
& (1.52 / \mathrm{HDL}) \\
\text { Where, } & \text { WC in inches, } \mathrm{BMI} \text { in } \mathrm{k} / \mathrm{m}^{2}, \mathrm{TG} \text { and HDL values }
\end{aligned}
$$

in $\mathrm{mg} / \mathrm{dl}$.

Calculation of Ankle brachial index was done by dividing the systolic blood pressure at the ankle by the systolic blood pressure at the brachial region (Qaisi et al., 2009). Measurement of ABI was done by using a Doppler with a $5-\mathrm{mHz}$ probe. Measurement of systolic blood pressure of brachial artery, dorsalis pedis artery, and tibial artery was estimated in the supine position for this purpose The maximum value of each systolic blood pressure measurement is and the cutoff point $<0.90$ is used for evaluating peripheral artery diseases (Criqui et al., 2010; Doobay et al., 2005; Hiatt et al., 1990; Resnick et al., 2004). The laboratory values for fasting blood glucose, total cholesterol, triglycerides, HDL, low density lipoprotein (LDL), glycosylated hemoglobin $\left(\mathrm{HBA}_{1} \mathrm{C}\right)$ were obtained and patients were stratified into risk categories for lipoprotein and total cholesterol (TC)/HDL ratio based on the National cholesterol education program, adult treatment panel III guidelines (NCEP-ATP III, 2002).

$\mathrm{D}$ Agostino et al. derived sex-specific general risk prediction equation was used for the assessment of 10 year cardiovascular risk (Kanjilal et al., 2008). Patient above 75 years were excluded from the study to avoid erroneous risk scores. Age, systolic blood pressure, treatment of hypertension, smoking status, diabetes status, total cholesterol, and HDL were used in the Framingham risk score. Subjects were stratified into high $(>20 \%)$, moderate $(10 \%-20 \%)$, and low $(<10 \%)$ risk of CVD (NCEP ATP III, 2002) based on the total risk score calculated.

\section{Statistical analysis}

For statistical validation, all data were evaluated by using IBM SPSS version 25 software. All the values were expressed as mean \pm standard error (SE). Gender difference in the mean values of variables was obtained by an independent $t$-test. A test of significance, that is chi-square test, was performed for comparison of distribution of risk factors in males and females and according to the 10-year risk level of occurrence of cardiovascular events. Two-tailed probability $p$ value $<0.05$ was considered significant.

\section{RESULTS}

Mean and SEs of the baseline demographic data of diabetic patients have been shown in Table 1. Mean age and age 
Table 1. Mean and SE of different cardiovascular risk factors of diabetic patients.

\begin{tabular}{|c|c|c|c|c|c|}
\hline Variables & Total $(N=118)$ Mean \pm SE & Males $(N=65)$ Mean $\pm \mathrm{SE}$ & Females $(N=53)$ Mean $\pm \mathrm{SE}$ & $t$-value & $p$-value \\
\hline Age (years) & $57.67 \pm 0.99$ & $56.5 \pm 1.39$ & $59.11 \pm 1.411$ & 0.103 & 0.912 \\
\hline Age of onset (years) & $51.37 \pm 1.053$ & $48.53 \pm 1.365$ & $53.54 \pm 1.543$ & 0.464 & 0.643 \\
\hline Duration (years) & $7.037 \pm 5.94$ & $8.09 \pm 0.82$ & $5.92 \pm 0.68$ & 0.068 & 0.945 \\
\hline Height $(\mathrm{cm})$ & $162.59 \pm 0.881$ & $167.38 \pm 1.094$ & $156.28 \pm 0.800$ & 2.49 & 0.014 \\
\hline Weight (kg) & $68.95 \pm 1.043$ & $70.68 \pm 1.449$ & $66.37 \pm 1.343$ & 2.068 & 0.040 \\
\hline Body mass index $\left(\mathrm{Kg} / \mathrm{m}^{2}\right)$ & $26.33 \pm 0.35$ & $25.74 \pm 0.45$ & $27.05 \pm 0.53$ & 2.080 & 0.039 \\
\hline Waist Circumference (inches) & $37.99 \pm 0.443$ & $38.93 \pm 0.678$ & $36.90 \pm 0.501$ & 0.183 & 0.854 \\
\hline Waist hip ratio & $0.96 \pm 0.009$ & $0.98 \pm 0.012$ & $0.94 \pm 0.011$ & 2.856 & 0.005 \\
\hline Waist height ratio & $0.58 \pm 0.007$ & $0.58 \pm 0.011$ & $0.59 \pm 0.007$ & 2.647 & 0.009 \\
\hline Systolic blood pressure $(\mathrm{mm} / \mathrm{Hg})$ & $131.82 \pm 1.549$ & $133.12 \pm 1.927$ & $130.22 \pm 2.514$ & 2.019 & 0.045 \\
\hline Diastolic Blood Pressure $(\mathrm{mm} / \mathrm{Hg})$ & $83.45 \pm 0.952$ & $84.20 \pm 1.347$ & $82.92 \pm 1.369$ & 2.581 & 0.0111 \\
\hline Ankle Blood pressure (mm/Hg) & $137.32 \pm 1.763$ & $137.03 \pm 2.072$ & $136.75 \pm 2.759$ & 0.182 & 0.855 \\
\hline Ankle—Brachial Index & $1.035 \pm 0.012$ & $1.02 \pm 0.01$ & $1.04 \pm 0.02$ & 2.740 & 0.007 \\
\hline Total cholesterol (mg/dl) & $174.55 \pm 4.333$ & $165.35 \pm 4.592$ & $185.83 \pm 7.602$ & 2.203 & 0.029 \\
\hline Triglycerides (mg/dl) & $172.18 \pm 6.30$ & $172.86 \pm 8.075$ & $171.35 \pm 10.020$ & 2.092 & 0.038 \\
\hline $\operatorname{LDL}(\mathrm{mg} / \mathrm{dl})$ & $104.14 \pm 2.887$ & $99.61 \pm 3.636$ & $108.98 \pm 4.549$ & 0.215 & 0.987 \\
\hline HDL (mg/dl) & $34.79 \pm 0.871$ & $33.3 \pm 1.088$ & $36.62 \pm 1.379$ & 2.060 & 0.041 \\
\hline $\mathrm{TC} / \mathrm{HDL}$ ratio & $5.24 \pm 0.143$ & $5.29 \pm 0.198$ & $5.18 \pm 0.209$ & 0.311 & 0.755 \\
\hline Fasting blood glucose (mg/dl) & $151.29 \pm 6.194$ & $148.01 \pm 08.354$ & $154.62 \pm 9.365$ & 2.307 & 0.022 \\
\hline Post-prandial blood sugar (mg/dl) & $222.26 \pm 7.737$ & $211.7 \pm 8.99$ & $233.7 \pm 13.26$ & 0.008 & 0.993 \\
\hline $\mathrm{HbA}_{1} \mathrm{C}$ (percent) & $7.91 \pm 0.205$ & $7.88 \pm 0.293$ & $7.96 \pm 0.290$ & 2.029 & 0.047 \\
\hline VAI & $393.26 \pm 24.40$ & $339.83 \pm 23.374$ & $461.90 \pm 44.55$ & 2.137 & 0.034 \\
\hline Framingham risk score & $10.64 \pm 0.814$ & $14.661 \pm 1.109$ & $5.72 \pm 0.786$ & 2.024 & 0.045 \\
\hline
\end{tabular}

The bold values represent statistically significant values.

of onset of the disease were lower in males (56.5 \pm 1.39 years), $(48.53 \pm 1.365$ years $)$ than in females $(59.11 \pm 1.411$ years $),(53.54$ \pm 1.543 years $)$, respectively. Duration of diabetes was higher in males $(8.09 \pm 0.82$ years $)$ than in females $(5.92 \pm 0.68$ years $)$. Males were significantly taller $(167.38 \pm 1.09 \mathrm{~cm})$ and heavier $(70.68 \pm$ $1.44 \mathrm{~kg}$ ) than females (height:- $156.28 \pm 0.80 \mathrm{~cm}$ ), (weight:- 66.37 $\pm 1.343 \mathrm{~kg})$, but later had higher BMI $\left(27.05 \pm 0.53 \mathrm{~kg} / \mathrm{m}^{2}\right)$ as compared with males $\left(25.74 \pm 0.45 \mathrm{~kg} / \mathrm{m}^{2}\right)$. Mean and SE values for central adiposity (waist circumference and WHR) was higher in males $38.93 \pm 0.678$ inches and $0.98 \pm 0.0012$ than females $36.90 \pm 0.50$ inches and $0.94 \pm 0.011$, respectively, But, WHtR was slightly higher in females $(0.59 \pm 0.007)$ than males $(0.58$ $\pm 0.011)$; systolic blood pressure (SBP), diastolic blood pressure (DBP), and ABP were slightly higher in males than females. ABI $(1.035 \pm 0.012)$ and triglycerides $(172.18 \pm 6.30 \mathrm{mg} / \mathrm{dl})$ got statistically significant values as cardiovascular risk factors with no gender difference. FBS, HbA1c, VAI, and Framingham risk score were statistically significant.

Gender wise distributions of patients in different categories of cardiovascular risk factors have been presented in Table 2. The data show that overall $55(46.61 \%)$ were overweight, of which 30 were male and 25 were female. Central obesity was more frequent among female patients waist circumference 37 (69.8\%) and WHtR 51 (96.22\%), than males waist circumference 14 (21.5\%) and WHtR 46 (70.76\%). Common cardiovascular risk factors such as total cholesterol and HDL are statistically significant. Considering low levels of HDL as a CVD risk factor, males $(75.3 \%)$ are at high risk and females $(60.37 \%)$ are at high risk. HBA1c as a risk factor of total patient $(83.05 \%)$ are at risk and the data show that males are high risk and with poor glycemic control. Study also shows that smoking and alcohol were in statistically significant as CVD risk factor. Patients were of family history of CVD irrespective of gender stratification were $35.59 \%$. Considering central adiposity WC, WHtR, and WHR, the total percentage of patients who were at risk are as follows: $43.2 \%, 82.2 \%$, and $83.1 \%$, respectively. About $83(72.02 \%)$ patients were at high risk according to VAI and of which males $(70.7 \%)$ and in females $(71.6 \%)$ are at high risk. According to sleep apnea, $79.66 \%$ were at moderate risk with no gender difference.

The distribution of risk factors for CVD, according to the 10-year cardiovascular risk level was shown in Table 3. According to weight wise risk stratification the incidence of high risk (53.8\%), moderate risk (43.6\%) and low risk (42.4\%) were observed. Smokers were at significant predictors for CVD, of them smokers were at high risk $(76.9 \%)$, moderate risk (48.7\%), and low risk (10.6\%) for future CVD. And, among the patients with high probability for future cardiovascular risk hypertensive $(69.2 \%)$ and pre-hypertensive $(30.8 \%)$ probably for moderate CVD risk levels, as per systolic blood pressure there were hypertensive (41.0\%) and pre-hypertensive (35.9\%). With respect to diastolic blood pressure, the patients with high risk for CVD were stratified among them hypertensive (15.4\%) and pre-hypertensive (38.5\%). VAI which is the indicator for the assessment of central obesity in patients was also in significant relationship with cardiovascular risk levels. Among that the patients with high risk were with abnormal VAI (92.3\%) and with moderate risk (76.9\%) were with abnormal VAI. And, in patients with high risk for CVD were at abnormal WHtR $(61.5 \%)$ and subjects with moderate risk for CVD were at abnormal WHtR (74.4\%).

Figure 1 shows the overall estimated risk score for the present population using Framingham CVD risk score in males and females. The severe risk was found to be more in males $(16.9 \%)$ than females $(3.77 \%)$, moderate risk was found more in 
Maharana et al. / Journal of Applied Pharmaceutical Science 9 (04); 2019: 126-132

Table 2. Gender wise distribution diabetic patients in categories of cardiovascular risk factors.

\begin{tabular}{|c|c|c|c|c|c|c|}
\hline Variables & Categories & $\begin{array}{l}\text { Overall percentage } \\
\text { (nos) }\end{array}$ & $\begin{array}{c}\text { Male percentage } \\
\text { (nos) }\end{array}$ & $\begin{array}{c}\text { Female percentage } \\
\text { (nos) }\end{array}$ & Chi-square & $p$ value \\
\hline \multirow[t]{4}{*}{ BMI } & Underweight & $2.54(3)$ & $3.07(2)$ & 0 & 2.60 & 0.45 \\
\hline & Normal & $29.66(35)$ & $40(26)$ & $35.8(19)$ & & \\
\hline & Overweight & $46.61(55)$ & $46.15(30)$ & $47.2(25)$ & & \\
\hline & Obese & $21.18(25)$ & $10.79(7)$ & $17(9)$ & & \\
\hline \multirow[t]{2}{*}{ Physical Activity } & Yes & 33.05 (39) & $47.69(31)$ & $15.09(8)$ & 14.02 & 0.001 \\
\hline & No & $66.9(79)$ & $52.3(34)$ & $84.9(45)$ & & \\
\hline Family History & Yes & $35.59(42)$ & $18.46(12)$ & $20.75(11)$ & 0.98 & 0.754 \\
\hline CVD & No & $64.4(76)$ & $81.53(53)$ & $79.24(42)$ & & \\
\hline \multirow[t]{2}{*}{ Smoke/tobacco } & Yes & $30.5(36)$ & $49.23(32)$ & $7.54(4)$ & 23.927 & 0.001 \\
\hline & No & $69.49(82)$ & $50.76(33)$ & 92.45 (49) & & \\
\hline \multirow[t]{2}{*}{ Alcoholic } & Yes & $37.28(44)$ & $60(39)$ & $9.43(5)$ & 31.92 & 0.001 \\
\hline & No & $62.71(74)$ & $40(26)$ & $90.56(48)$ & & \\
\hline \multirow[t]{2}{*}{ History of CKD } & Yes & $22.88(27)$ & $18.46(12)$ & $28.3(15)$ & 1.602 & 0.206 \\
\hline & No & $77.11(91)$ & $81.53(53)$ & $71.69(38)$ & & \\
\hline \multirow[t]{3}{*}{ SBP } & Normal & $29.66(35)$ & $24(16)$ & $35.84(19)$ & 2.394 & 0.302 \\
\hline & Pre-HTN & $34.74(41)$ & $40(26)$ & $28.3(15)$ & & \\
\hline & Hypertensive & $35.59(42)$ & $36(24)$ & 35.84 (19) & & \\
\hline \multirow[t]{3}{*}{ DBP } & Normal & $59.32(70)$ & $55.4(36)$ & $62.26(33)$ & 1.972 & 0.373 \\
\hline & Pre-HTN & $0.84(1)$ & $3.1(1)$ & 0 & & \\
\hline & Hypertensive & $39.8(47)$ & $41.5(27)$ & $37.73(20)$ & & \\
\hline \multirow[t]{3}{*}{$\mathrm{ABI}$} & $0.9-1.2$ & $69.5(82)$ & $74.6(47)$ & $63.6(35)$ & 1.959 & 0.376 \\
\hline & $<0.9$ & $11.0(13)$ & $17.5(11)$ & $21.8(12)$ & & \\
\hline & $>1.2$ & $19.5(23)$ & $7.9(5)$ & $14.5(8)$ & & \\
\hline \multirow[t]{2}{*}{ FBS } & Normal & $33.89(40)$ & $35.38(23)$ & 32.07 (17) & 0.143 & 0.706 \\
\hline & Risk & $66.10(78)$ & $64.61(42)$ & $67.92(36)$ & & \\
\hline \multirow[t]{2}{*}{ PPBS } & Normal & $16.94(20)$ & $20(13)$ & $13.2(7)$ & 0.957 & 0.328 \\
\hline & Risk & $83.05(98)$ & $80(52)$ & $86.79(46)$ & & \\
\hline \multirow[t]{2}{*}{ HBA1C } & Normal & $16.94(20)$ & 29.23 (19) & 32.07 (17) & 0.111 & 0.739 \\
\hline & Risk & $83.05(98)$ & $70.76(46)$ & $67.92(36)$ & & \\
\hline \multirow[t]{2}{*}{ Triglycerides } & Normal & $45.76(54)$ & $41.53(27)$ & $50.94(27)$ & 1.040 & 0.308 \\
\hline & Risk & $54.23(64)$ & $58.46(38)$ & $49.05(26)$ & & \\
\hline \multirow[t]{2}{*}{ Total cholesterol } & Normal & $38.9(47)$ & $18.46(12)$ & $66.03(35)$ & 27.574 & 0.001 \\
\hline & Risk & $60.16(71)$ & $81.53(53)$ & $33.96(18)$ & & \\
\hline \multirow[t]{2}{*}{ LDL } & Normal & $82.2(97)$ & $84.6(55)$ & 79.24 (42) & 0.575 & 0.448 \\
\hline & Risk & $17.8(21)$ & $15.38(10)$ & $20.75(11)$ & & \\
\hline \multirow[t]{2}{*}{ HDL } & Normal & $29.7(37)$ & $24.61(16)$ & $39.62(21)$ & 4.576 & 0.032 \\
\hline & Risk & $70.3(81)$ & 75.38 (49) & $60.37(32)$ & & \\
\hline \multirow[t]{2}{*}{ TC/HDL ratio } & Normal & $49.15(58)$ & $44.6(29)$ & $54.71(29)$ & 1.192 & 0.275 \\
\hline & Risk & $50.84(60)$ & $55.3(36)$ & $45.28(24)$ & & \\
\hline \multirow[t]{2}{*}{ WC } & Normal & $56.8(67)$ & $78.5(51)$ & $30.2(16)$ & 27.72 & 0.001 \\
\hline & Risk & $43.2(51)$ & $21.5(14)$ & $69.8(37)$ & & \\
\hline \multirow[t]{2}{*}{ WHtR } & Normal & $17.79(21)$ & $29.23(19)$ & $3.77(2)$ & 12.933 & 0.001 \\
\hline & Risk & $82.2(97)$ & $70.76(46)$ & $96.22(51)$ & & \\
\hline \multirow[t]{2}{*}{ WHR } & Normal & $16.94(20)$ & $15.38(10)$ & $20.7(10)$ & 0.252 & 0.616 \\
\hline & Risk & $83.1(98)$ & $84.61(55)$ & $81.1(43)$ & & \\
\hline VAI & Normal & $27.96(35)$ & 29.23 (19) & $28.3(15)$ & 19.568 & 0.001 \\
\hline & Risk & $72.08(83)$ & $70.76(46)$ & $71.6(38)$ & & \\
\hline Sleep apnea & Mild & $16.1(19)$ & $16.92(11)$ & $15.09(8)$ & 4.47 & 0.107 \\
\hline & Moderate & $79.66(94)$ & $75.38(49)$ & $84.9(45)$ & & \\
\hline & Severe & $4.23(5)$ & $7.69(5)$ & 0 & & \\
\hline Framingham & Mild & $55.93(66)$ & $32.3(21)$ & $84.9(45)$ & 32.769 & 0.001 \\
\hline & Moderate & 33.05 (39) & $50.7(33)$ & $11.32(6)$ & & \\
\hline & Severe & $11.01(13)$ & $16.9(11)$ & $3.77(2)$ & & \\
\hline
\end{tabular}

The bold values represent statistically significant values. 
Table 3. Cross tabulation of risk factors and 10-year cardiovascular risk level.

\begin{tabular}{|c|c|c|c|c|c|c|}
\hline \multirow{2}{*}{ Variables } & \multirow{2}{*}{ Categories } & \multicolumn{3}{|c|}{ 10-year cardiovascular risk level in percentage (nos) } & \multirow{2}{*}{ Chi-square } & \multirow{2}{*}{$p$ value } \\
\hline & & Low & Moderate & High & & \\
\hline \multirow[t]{4}{*}{ BMI } & Underweight & $1.5(1)$ & $2.6(1)$ & 0 & 1.800 & 0.937 \\
\hline & Normal & $37.9(25)$ & $33.3(13)$ & $38.5(5)$ & & \\
\hline & Overweight & $42.4(28)$ & $43.6(17)$ & $53.8(7)$ & & \\
\hline & Obese & $18.2(12)$ & $20.5(8)$ & $7.7(1)$ & & \\
\hline \multirow[t]{2}{*}{ Family History } & Yes & $21.2(14)$ & $15.4(6)$ & $23.1(3)$ & 0.650 & 0.722 \\
\hline & No & $78.8(52)$ & $84.6(33)$ & $76.9(10)$ & & \\
\hline \multirow[t]{2}{*}{ Smoke/tobacco } & Yes & $10.6(7)$ & 48.7 (19) & $76.9(10)$ & 31.64 & 0.001 \\
\hline & No & $89.4(59)$ & $51.3(20)$ & $23.1(3)$ & & \\
\hline \multirow[t]{2}{*}{ History of CKD } & Yes & $18.2(12)$ & $30.8(12)$ & $23.1(3)$ & 2.201 & 0.333 \\
\hline & No & $81.8(54)$ & $69.2(27)$ & $76.9(10)$ & & \\
\hline \multirow[t]{3}{*}{ SBP } & Normal & $46.4(26)$ & $23.1(9)$ & 0 & 12.549 & 0.014 \\
\hline & Pre-HTN & $27.3(18)$ & $35.9(14)$ & $30.8(4)$ & & \\
\hline & HTN & $30.3(20)$ & $41.0(16)$ & $69.2(9)$ & & \\
\hline \multirow[t]{3}{*}{ DBP } & Normal & $18.2(12)$ & $64.1(25)$ & $46.2(6)$ & 25.297 & 0.001 \\
\hline & Pre-HTN & $34.8(23)$ & $20.5(8)$ & $38.5(5)$ & & \\
\hline & HTN & $47(31)$ & $15.4(6)$ & $15.4(2)$ & & \\
\hline \multirow[t]{3}{*}{ ABI } & $0.9-1.2$ & $71 . .2(47)$ & $69.2(27)$ & $53.8(7)$ & 3.854 & 0.426 \\
\hline & $<0.9$ & $12.1(8)$ & $20.5(8)$ & $30.8(4)$ & & \\
\hline & $>1.2$ & $16.7(11)$ & $10.3(4)$ & $15.4(2)$ & & \\
\hline \multirow[t]{2}{*}{ HBA1C } & Normal & $31.8(21)$ & $30.8(12)$ & $15.4(2)$ & 1.440 & 0.487 \\
\hline & Risk & $68.2(45)$ & $69.2(27)$ & $84.6(11)$ & & \\
\hline \multirow[t]{2}{*}{ FBS } & Risk & $66.7(44)$ & $71.8(28)$ & $61.5(8)$ & 0.557 & 0.757 \\
\hline & Normal & $33.3(22)$ & $28.2(11)$ & $38.5(5)$ & & \\
\hline \multirow[t]{2}{*}{ Triglycerides } & Normal & $60.6(40)$ & $82.1(32)$ & $84.6(11)$ & 6.831 & 0.033 \\
\hline & Risk & $39.4(26)$ & $17.9(7)$ & $15.4(2)$ & & \\
\hline \multirow[t]{2}{*}{ Total Cholesterol } & Normal & $71.2(47)$ & $74.4(29)$ & $84.6(11)$ & 1.019 & 0.61 \\
\hline & Risk & $28.8(19)$ & $25.6(10)$ & $15.4(2)$ & & \\
\hline \multirow[t]{2}{*}{ LDL } & Normal & $84.8(56)$ & $73.2(30)$ & $81.8(9)$ & 2.211 & 0.331 \\
\hline & Risk & $15.2(10)$ & $26.8(11)$ & $18.2(2)$ & & \\
\hline \multirow[t]{2}{*}{ HDL } & Normal & $62.1(41)$ & 74.4 (29) & $76.9(10)$ & 2.239 & 0.326 \\
\hline & Risk & $37.9(25)$ & $25.6(10)$ & $23.1(3)$ & & \\
\hline \multirow[t]{2}{*}{ TC/HDL ratio } & Normal & $83.3(55)$ & $74.4(29)$ & $61.5(8)$ & 3.444 & 0.179 \\
\hline & Risk & $16.7(11)$ & $25.6(10)$ & $38.5(5)$ & & \\
\hline \multirow[t]{2}{*}{ WC } & Normal & $47.0(31)$ & $66.7(26)$ & $76.9(10)$ & 6.291 & 0.043 \\
\hline & Risk & $53(35)$ & $33.3(13)$ & $23.1(3)$ & & \\
\hline \multirow[t]{2}{*}{ WHtR } & Normal & $10.6(7)$ & $25.6(10)$ & $38.5(5)$ & 7.436 & 0.024 \\
\hline & Risk & $89.4(59)$ & 74.4 (29) & $61.5(8)$ & & \\
\hline WHR & Normal & $21.2(14)$ & $10.3(4)$ & 15.4 (2) & 2.116 & 0.347 \\
\hline & Risk & $78.8(52)$ & $89.7(35)$ & $84.6(11)$ & & \\
\hline VAI & Normal & $37.9(25)$ & $23.1(9)$ & $7.7(1)$ & 5.954 & 0.05 \\
\hline & Risk & $82.1(41)$ & $76.9(30)$ & $92.3(12)$ & & \\
\hline Sleep apnea & Mild & $21.2(14)$ & $10.3(4)$ & $15.4(2)$ & 3.127 & 0.537 \\
\hline & Moderate & $75.8(50)$ & $82.1(32)$ & $76.9(10)$ & & \\
\hline & Severe & $3(2)$ & $7.7(3)$ & $7.7(1)$ & & \\
\hline Duration of DM & $<5$ years & $48.5(32)$ & $41.0(16)$ & $30.8(4)$ & 6.608 & 0.158 \\
\hline & $5-10$ years & $34.8(23)$ & $41.0(16)$ & $23.1(3)$ & & \\
\hline & $>10$ years & $16.7(11)$ & $17.9(7)$ & $46.2(6)$ & & \\
\hline
\end{tabular}

The bold values represent statistically significant values. 


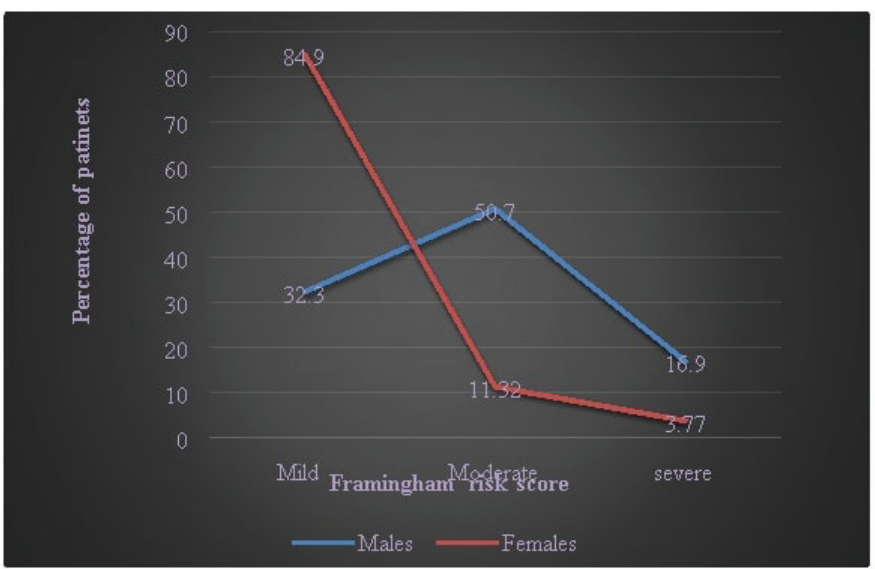

Figure 1. Framingham risk score versus percentage of patients. The overall estimated risk score for the present population using Framingham CVD risk score in males and females.

males $(50.7 \%)$ than females $(11.32 \%)$. The mild risk was less in males $(32.3 \%)$ than female patients $(84.9 \%)$.

\section{DISCUSSION}

In this study, 10-year risk of developing CVD among the type-2 diabetes mellitus patients without the history of CVD and the probable risk factors were evaluated on the basis of Framingham risk scores. Results revealed that $11.1 \%$ of the subjects were at high risk, 33.05\% were at moderate risk, and 55.93\% were at low risk for CVD. This states that the Framingham risk score underestimates the risk of Indian population. Similar findings have been reported by Kanjilal et al. (2008) study where only $5 \%$ of the considered subjects were estimated to be at high risk. Males were at higher risk for CVD than compared with females. Similar findings has been reported by Gomes et al. (2009) among Brazilian diabetes mellitus subjects which contradicts with the earlier studies which reports high CVD mortality in women (Hu et al., 2005; Kanaya et al., 2002). Some clinical trials investigating the efficacy of improving glycemic control have also reported a reduction in the risk of cardiovascular events. However, some recent trails have demonstrated contradicting findings with no significant improvement in cardiovascular risk as a consequence of intensive glucose lowering therapy (Laakso et al., 2010). In the present study, systolic blood pressure, diastolic blood pressure, smoking, triglycerides, and central obesity parameters such as waist circumference, WHtR, and VAI have contributed significantly to the high risk of developing CVD in the next 10 years according to the Framingham risk score. Among Manipur population, Mary Grace et al. (2014) had showed the similar findings excluding diastolic blood pressure and VAI. On the other hand in the present study, a group of large number of patients have uncontrolled glycemic condition may be mainly due to sedentary life style and intake of high glycemic index food such as rice. A study conducted by Key et al. (1999) have reported that there is $28 \%$ reduced chance of developing heart disease among vegetarians than non-vegetarians due to lower serum total cholesterol concentrations, when adjusted for the impact of BMI. This study supports the current findings that triglycerides are in significant relationship with the cardiovascular risk levels. Narkiewicz et al. (2017) demonstrated that patients with severe risk of sleep apnea are at high increased risk for CVD. Contradict to that study our study shows there is no significant relationship of sleep apnea with CVD risk levels. The correlation of VAI to all metabolic syndrome factors, cerebrovascular, and cardiovascular events was established. This situation is resultant of high triglycerides, low HDL, and visceral obesity related with age linked insulin and leptin resistance. VAI is an easily applicable tool for the evaluation of visceral fat dysfunction. It cannot be a tool for diagnosis of cerebro-vascular and cardiovascular events. It simplifies the assessment of HDL, triglycerides, BMI, and waist circumference (Marco et al., 2010). In our study, we could not able to find any significant relationship of ABI with CVD risk levels. Earlier studies have been concluded that the ABI was considered as an independent tool for risk prediction and superior to Framingham score. Criqui et al. (2010) has demonstrated that less the $\mathrm{ABI}$ value higher the cardiovascular risk.

\section{STUDY LIMITATIONS}

The present study results are only limited to type 2 diabetic patients not having any history of CVD and it does not assess the risk of diabetic patients with previous history of CVD. Also, the study is limited to only type-2 diabetes mellitus patients who are free from immune compromised disease such as HIV. This study was restricted only to southern part of India with less number of samples.

\section{CONCLUSION}

This study concluded that study population of patient's (type-2 diabetes mellitus) estimated cardiovascular risk was in relationship with the central obesity parameters such as visceral adiposity index, but not with glycemic control parameters. From this, it can be suggested that better control over risk factors and proper lifestyle modification tools can prevent the increasing incidence of CVD risk among diabetic individuals. The use of cardiovascular risk assessment tools like Framingham risk score, WHtR, WHR, visceral adiposity index, and ankle brachial index can help in the assessment of CVD in diabetic patients.

\section{CONFLICT OF INTEREST}

The authors declare that they have no conflict of interest.

\section{REFERENCES}

American Diabetes Association. Standard of medical care in diabetes. Diabetes Care, 2005; 28(1):5-36.

Ashwell M. Waist to height ratio and the Ashwell shape chart could predict the health the health risks of obesity in adults and children in all ethnic groups. Nutr Food Sci, 2005; 35(5):359-64.

Bitton A, Gaziano TA. The Framingham heart study's impact on global risk assessment. Prog Cardiovasc Dis, 2010; 53(1):68-78. York, NY, 1977.

Cochran WG. Sampling techniques. John Wiley \& Sons, New

Conroy RM, Pyorala K, Fitzgerald AP. Estimation of ten-year risk of fatal cardiovascular disease in Europe: the SCORE project. Eur Heart J, 2003; 24:987-1003.

Criqui MH, McClelland RL, McDermott MM, Allison MA, Blumenthal RS, Aboyans V, Ix JH, Burke GL, Liu K, Shea S. The anklebrachial index and incident cardiovascular events in the MESA (MultiEthnic Study of Atherosclerosis). J Am Coll Cardiol, 2010; 56(18):1506-12.

Doobay AV, Anand SS. Sensitivity and specificity of the anklebrachial index to predict future cardiovascular outcomes: a systemic review. Arterioscler Thromb Vasc Biol, 2005; 25(7):1463-9. 
Gomes MB, Giannella Neto, Faria M. Estimating cardiovascular risk in patients with type-2 diabetes: a national multicenter study in Brazil. Diabetol Metab Syndr, 2009; 1:22-8.

Grundy SM, Balady GJ, Criqui MH. Primary prevention of coronary heart disease: guidance from Framingham: a statement for healthcare professionals from the AHA task force on risk reduction. American heart association. Circulation, 1998; 97(18):1876-87.

Grundy SM, Benjamin IJ, Burke GL. AHA scientific statement. Diabetes and cardiovascular disease. A statement for healthcare professionals from the American Heart Association. Circulation, 1999; 100:1134-46.

Gu K, Cowie CC, Harris MI. Diabetes and decline in heart disease mortality in US adults. JAMA, 1999; 281(14):1291-7.

$\mathrm{Gu} \mathrm{K}$, Cowie CC, Harris MI. Mortality in adults with and without diabetes in a national cohort of the U.S. population. Diabetic Care, 1998; 21(7):1135-22.

Haffner SM, Lehto S, Roinnemaa T, Pyorala K, Laakso M. Mortality from coronary heart disease in subjects with type-2 diabetes and in non-diabetic subjects with and without prior myocardial infarction. N Engl J Med, 1998; 339:229-34.

Hiatt WR, Marshall JA, Baxter J, Sandoval R, Hildebrandt W, Kahn LR. Diagnostic study. J Clin Epidemiol, 1990; 43(6):597-606.

Hippisley-Cox J, Coupland C, Vinogradova Y. Predicting cardiovascular risk in England and Wales: prospective derivation and validation of QRISK2. BMJ, 2008; 336(7659):1475-82.

Hu G, Jousilahti P, Qiao Q, Katoh S, Tuomilehto J. Sex differences in cardiovascular and total mortality among diabetic and nondiabetic individuals with or without history of myocardial infarction. Diabetologia, 2005; 48(5):856-61.

Kanaya AM, Grady D, Barrett-Connor E. Explaining the sex difference in coronary heart disease mortality among patients with type2 diabetes mellitus: a meta-analysis. Arch Intern Med, 2002; 162(15): $1737-45$.

Kanjilal S, Rao VS, Mukherjee M. Application of cardiovascular disease risk prediction models and the relevance of novel biomarkers to risk stratification in Asian Indians. Vasc Health Risk Manag, 2008; 4:199-211.

Key TJ, Fraser GE, Thorogood M, Appleby PN, Beral V, Reeves G, Burr ML, Chang-Claude J, Frentzel-Beyme R, Kuzma JW, Mann J, McPherson K. Mortality in vegetarians and non vegetarians: detailed findings from a collaborative analysis of 5 prospective studies, Am J Clin Nutr, 1999; 70(3 Suppl):516S-24S.

Knowles KM, Paiva LL, Sanchez SE. Waist circumference, body mass index and other measures of adiposity in predicting CVD risk factors among Peruvian adults. Int J Hyperten, 2011; 2011:931402.

Laakso M. Cardiovascular disease in type 2 diabetes from population to man to mechanisms. Diabetes Care, 2010; 33(2):442-49.

Marco C, Amato MD, Carla Giordano MD, Angela criscimanna MD. Salvatore vitabile, BSC, MSC, Visceral adiposity index a reliable indicator of visceral fat function association with cardio metabolic risk American diabetes association, 2010; 33:920-2.
Mary Grace T, Ginzaniang T, Poufullung K. Risk of cardiovascular disease among diabetic patients in Manipur, Northeast India. J Anthropol, 2014; Article ID 421439:9.

Narkiewicz K. Altered cardiovascular variability in obstructive sleep apnea. Circulation, 2017; 21:1071-7.

Qaisi Al, Nott M, King DM, Kaddoura S. Ankle brachial pressure index: an update for practitioners. Vasc Health Risk Manag, 2009; 5:833-41.

Resnick HE, Lindsay RS, McDermott MM, Devereux RB, Jones KL, Fabsitz RR, Howard BV. Relationship of high and low ankle brachial index to all-cause and cardiovascular disease mortality: the strong heart study. Circulation, 2004; 109(6):733-9.

Ridker PM, Buring JE, Rifai N. Development and validation of improved algorithms for the assessment of global cardiovascular risk women: the Reynolds risk score. JAMA, 2007; 297(6):611-9.

Sarwar N, Gao P, Seshasai SR, Gobin R, Kaptoge S. Emerging risk factors diabetes mellitus, fasting blood glucose concentration and risk of vascular disease; a collaborative meta-analysis of 102 prospective studies. Lancet, 2010; 375(9733):2215-22.

Seshasai SR, Kaptoge S, Thompson A. Diabetes mellitus, fasting glucose and risk of cause of specific death. The new England general of medicine. 2011; 3641:829-41.

Third report of the national cholesterol education program (NCEP) expert panel on detection, evaluation, and treatment of high blood cholesterol in adults (adult treatment panel III) final report. Circulation, 2002; 106(25):3143-21.

Thurtell MJ, Bruce BB, Rye DB, Newman NJ, Biousse V. The berlin questionnaire screens for obstructive sleep apnea in idiopathic intracranial hypertension. J Neuroophthalmol, 2011; 31(4):316-9.

Weiner JS, Lourie JA (eds.). Practical human biology. Academic press, London, UK, 1981.

World Health Organization. Diet, nutrition and prevention of chronic disease. Report of a joint WHO/FAO expert consultation, Tech. Rep. 916, 2003.

How to cite this article:

Maharana L, Reddy SK, Pattnaik S, Ahmed S, Teja D, Hargavi BM, Hussain SS, Sethi MK. A prospective observational study on cardiovascular risk assessment in type-2 diabetes mellitus patients. J Appl Pharm Sci, 2019; 9(04):126-132. 